\title{
(2) OPEN ACCESS \\ Early-life social and health determinants of adult socioeconomic position: associations and trends across generations
}

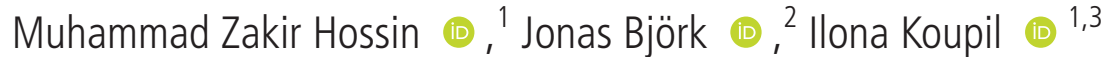

- Additional material is published online only. To view please visit the journal online (http://dx.doi.org/10.1136/ jech-2019-213209)

'Department of Global Public Health, Karolinska Institute, Stockholm, Sweden

${ }^{2}$ Department of Occupational and Environmental Medicine, Lunds Universitet, Lund, Sweden ${ }^{3}$ Department of Public Health Sciences, Stockholm University, Stockholm, Sweden

\section{Correspondence to} Muhammad Zakir Hossin, Department of Global Public Health, Karolinska Institute, Stockholm 171 65, Sweden; zakir.hossin@ki.se

Received 11 September 2019 Revised 23 December 2019 Accepted 11 January 2020 Published Online First 27 January 2020

\begin{abstract}
Background Social and biological circumstances at birth are established predictors of adult socioeconomic position (SEP). This study aims to assess the trends in these associations across two generations and examine the effects of parental early-life characteristics on descendants' adult SEP.

Methods We studied men and women born in the Uppsala University Hospital 1915-1929 (G1) and their offspring born 1932-1960 (G2). Data were collected in archives and routine registers. Adult SEP was assessed as an aggregate measure combining education and occupation. The exposures were family SEP, mother's marital status, mother's parity, mother's age, standardised birth weight, gestational length and birth multiplicity. Linear regression was used to examine the associations across generations.
\end{abstract}

Results The difference in adult SEP between low and high family SEP at birth was 15.8 (95\% Cl: 13.3 to 18.3 ) percentage points smaller in $\mathrm{G} 2$ compared with $\mathrm{G} 1$, although a considerable difference was still evident in G2. The associations of adult SEP with small birth weight for gestational age, post-term birth and high parity were stable between the generations: the generational differences in adjusted coefficients were 1.5 (95\% Cl: -1.1 to 4.1), 0.6 (-1.7 to 2.9) and 1.8 (-0.2 to 3.8$)$ percentage points, respectively. The association between grandparental and grandchildren's SEPs was largely explained by parental socioeconomic conditions. Father's preterm birth was independently associated with offspring's SEP.

Conclusion The stability of the associations between early-life biological disadvantages and adult SEP and the persistent, although attenuated, association between early-life and adult SEPs necessitates increased policy attention to both social and health conditions at birth.

\section{INTRODUCTION}

A challenge in public health is the persistent health inequalities between educational and occupational groups. The socioeconomic gradient in health continues to exist even in societies with generous welfare arrangements. ${ }^{12}$ The genesis of the socioeconomic gradient in health is conventionally explained by two theoretical frameworks: social causation and health selection. In view of the social causation approach, socioeconomic position (SEP) determines health while the health selection approach posits that health status itself or health determinants influence SEP through selection into higher social positions since the healthier persons are more likely to move up the social hierarchy. ${ }^{3}$

Individuals are not randomly allocated to adult social positions and health statuses which have their systematic origins in early life $e^{4-6}$ and the current study draws on the life course approach to understand how early-life circumstances systematically set individuals onto different socioeconomic trajectories. Within this approach, both social and health conditions in the early stages of life are integrated into a single framework to predict the socioeconomic and health outcomes across the life course and across generations. ${ }^{7-9}$ While the health indicators at birth such as low birth weight or preterm birth are known to be constituting an important mechanism in the process of social stratification, they themselves tend to be socially patterned, implying a SEP-health gradient already taking place at birth. ${ }^{9} 10$ The advantaged socioeconomic conditions of parents may lead to offspring's upward social mobility by providing opportunities for education and employment. Socioeconomic conditions of the parents may also act through biological mechanisms by exposing the offspring to increased vulnerability to stress and malnutrition during pregnancy, thereby affecting fetal growth and development ${ }^{11} 12$ which, in turn, may lead to poorer SEP through cognitive, non-cognitive and biological pathways ${ }^{9}$ (See online supplementary figure 1).

Although the disadvantaged conditions at birth are often demonstrated to be associated with poorer cognitive, educational, labour market and health outcomes along the life span, ${ }^{13-16}$ little research has been carried out to examine whether the same associations are subject to changes in different historical contexts. With the advent of the modern social welfare regime in Sweden in the post-World War II period, dramatic changes in the social environment took place: opportunities for education and healthcare services were equalised, living standard was improved, a universal child allowance was introduced, infant mortality declined and childbearing outside of wedlock increasingly became socially acceptable. ${ }^{17-19}$ Given the large-scale egalitarian reforms, it is reasonable to assume that the impact of family social background and the associated earlylife biological conditions on subsequent educational and socioeconomic successes have attenuated over time. To monitor the early-life determinants of social and health inequalities and evaluate policy efforts to alter them, it is crucial to pay an explicit attention to the changing societal, political and historical contexts. $^{2021}$ 
One potential route through which early-life disadvantages may persist over time is intergenerational reproduction. There is ample intergenerational research linking parental social disadvantages to the educational and socioeconomic outcomes of their descendants. ${ }^{22-27}$ However, not much is known about the intergenerational influences of parents' early-life biological disadvantages on the offspring's socioeconomic achievements. Based on register data from two generations of Swedish families, the current study sought to answer two major research questions (see also online supplementary figure 2):

i. Have the associations of biological and social disadvantages at birth with SEP in adulthood changed across generations?

ii. Are the parent's biological and social conditions at birth associated with the offspring's adult SEP? Are these associations mediated by parents' adult socioeconomic circumstances?

\section{METHODS \\ Study populations}

The study base includes the first (G1) and the second (G2) generations of the Uppsala Multi-generational Birth Cohort Study. G1 comprise all live births in the Uppsala University Hospital in Sweden during 1915-1929. G2 was the biological offspring of G1 born 1932 and onwards. ${ }^{28}$

Of the 14192 members in G1, 12168 could be traced in registers through unique personal identification numbers. The study sample included 11937 individuals who were alive and living in Sweden until November 1960 (when the population and housing census was carried out). Of them, $86 \%(n=10233)$ had complete information on all study variables. Main analyses of G2 individuals were restricted to 9248 offspring of parents resident in the Uppsala region as obstetric records of individuals born elsewhere could not be obtained. A total of $7238 \mathrm{G} 2$ obstetric records were traced. We further excluded individuals born after $1960(n=335)$ to allow the study subjects to attain their occupational class at a minimum age of 30 during the latest census in 1990. Of the remaining 6903, $88 \%(n=6055)$ had complete data on all the study variables (See online supplementary figure 3 ). Our sensitivity analyses included all members of G2 with data on relevant social and demographic characteristics available.

\section{Measures}

Outcome

Adult SEP was assessed through Hollingshead's Index of Social Position (HISP), a measure aggregating occupation and education. $^{29} 30$ The 1960 Swedish census provided data on the occupation of G1 and 1980 and 1990 censuses on occupation of G2. The data on education were obtained from censuses and education registers until 2008 and the highest education ever achieved at age $21+$ years was used. Education was categorised on a 7-point hierarchical scale: (1) pre-secondary<9years, (2) compulsory 9 years, (3) upper secondary $\leq 2$ years, (4) upper secondary $>2$ years, (5) post-secondary $<3$ years, (6) postsecondary $\geq 3$ years and (7) postgraduate. Based on Statistics Sweden's socioeconomic classification scheme, ${ }^{31}$ occupation was also hierarchically arranged: (1) unskilled workers, (2) skilled workers, (3) self-employed other than professionals, (4) lower non-manuals, (5) mid-non-manuals, (6) upper non-manuals and (7) self-employed professionals. While we primarily used participant's own occupation to calculate the socioeconomic index, household head occupation was also used in G1 if own occupation was not available. The HISP is a weighted score calculated by multiplying the values of education and occupation (1-7) by the factor weights of 4 and 7, respectively. ${ }^{29} 303233$ The aggregated sum ranged from 11 to 77 , with a lower score indicating lower SEP. We transformed the HISP scores into percentages (range 0-100) to facilitate interpretations of the findings.

For sensitivity analysis, we divided the HISP scores within each generation into tertiles which, in turn, were dichotomised into advantaged SEP (highest tertile) and disadvantaged SEP (two lower tertiles). In addition, education and occupation were used as separate binary outcomes. Education was dichotomised as high (education higher than senior high school, ie, university level) and low ( $\leq$ senior high school). Occupation was dichotomised as advantaged (self-employed professionals and upper non-manual and mid-non-manual workers) and disadvantaged (lower non-manuals, self-employed other than professionals, skilled and unskilled workers).

\section{Exposures}

The exposures of interest were family SEP, mother's marital status at child birth, mother's parity, standardised birth weight, gestational age, multiplicity of birth and mother's age at child birth. Exposures were derived from archived obstetric, school and census 1930 records. Family SEP for G2 was based on 1960 census data. Birth weight was standardised for gestational weeks, separately for men and women. Using its percentile distribution, the standardised birth weight was then divided into three categories: small-for-gestational age defined as infants at the bottom 10th percentile; normal defined as infants between 10th and 90th percentiles; and large-for-gestational age defined as infants above the 90th percentile. Gestational age was grouped into preterm ( $\leq 36$ weeks), term (37-41 weeks) and post-term ( $\geq 42$ weeks) births. Multiplicity of birth was dichotomised as single and twin/triplet. Mother's parity was categorised into 1, 2 and $\geq 3$. Mother's marital status was dichotomised into married and unmarried (ie, single/divorced/widowed). Mother's age at child's birth was grouped as <20, 20-24, 25-29, 30-34 and $\geq 35$ years.

We assessed family SEP in G1 using father's occupation if recorded (80\%) and mother's occupation if father's occupation was not available (20\%). For G2, occupation of the household head from census 1960 was used. In both generations, family SEP was categorised as follows: high family SEP (self-employed professionals and the upper and intermediate non-manual workers); medium (lower non-manuals, military, farmers and the self-employed other than the professionals) and low (skilled and unskilled workers and parents with no occupation).

\section{Control variables}

The main control variables were year of birth and gender obtained from archived records and registers. For effect estimation of each specific exposure, additional confounders were chosen from the remaining exposures in line with the respective causal model. When assessing the effects of parents' earlylife exposures on offspring's adult SEP, parents' year of birth was used as a confounder and parent's education, occupation and equivalised disposable income as mediating variables. The highest income ever recorded at ages 30-64 years was standardised for age, gender and calendar year and was equivalised to account for the family size and composition.

\section{Statistical analyses}

Stata/SE V.15.0 was used for all analyses. The distributions of the early-life characteristics were assessed separately for the two generations. Linear regression models were fitted to estimate 
the effects and their 95\% CIs. The main statistical analysis was carried out at two stages:

First, we tested whether the associations between early-life exposures and adult SEP varied significantly between the two generations. This was done by fitting a regression model with a product term between each exposure of interest and generation, with a statistically significant interaction indicating a change of the studied association. The differences in the associations were assessed both in minimally and multiply adjusted models. The minimally adjusted models mainly controlled for year of birth as well as gender when appropriate. The multiply adjusted models additionally controlled for different sets of confounders relevant to the respective models. Any potential interaction between the exposures or effect modification by gender was also systematically explored and reported. To facilitate better comparison of the associations, the analyses were repeated using a restricted G2 sample born during 1945-1960 and the results were reported as supplementary.

The second stage of analysis focused on parent-to-offspring transmissions. The G2 study subjects were considered as the units of analysis and the associations between G1's early-life characteristics and G2's adult SEP were estimated separately along maternal and paternal lines. In addition to the confounding factors, we adjusted for parental education, occupation and income as mediators in the regression models. We accounted for the intra-cluster correlation in siblings by estimating robust standard errors in all statistical models.

Additional analyses using HISP, education and occupation as separate binary outcomes were based on logistic regression models. The results from logistic regression are presented as ORs in supplementary tables.

\section{RESULTS}

The distribution of the early-life characteristics of the two generations is shown in table 1 . There was a slightly higher prevalence of SGA and lower prevalence of preterm births in G2 compared with G1. The distribution of family SEP suggests a substantial upward trend from low to medium and high family SEP. The proportion of multiple births and mothers of higher parity declined over time and the number of younger mothers has risen considerably. Compared with the G2 sample, there was a higher representation of single mothers in G1.

The distribution of HISP scores was skewed to the right in both generations, with a higher proportion of individuals at the lower end of the scale (figure 1). When compared with G1, G2 had a relatively high concentration of individuals at the upper socioeconomic spectrum. The mean HISP scores in G1 and G2 were 31.1 (SD 25.1, median 31.8) and 38. 2 (SD 24.9, median 34.8), respectively, suggesting an upward intergenerational social mobility in the younger generation. The distribution of the HISP by early-life characteristics is presented in online supplementary table 1.

Table 2 displays the associations between early-life exposures and adult SEP as well as the differences in the associations between the two generations. Compared with high family SEP, low and medium SEPs showed substantially lower HISP scores in both generations. The effect size among individuals with low family SEP was found to be even greater in the whole G2 population (B: $-17.1 ; 95 \% \mathrm{CI}:-17.9$ to -16.3 ) in comparison with the studied G2. The early-life biological characteristicsbirth weight, gestational length and birth multiplicity-did not mediate the estimated associations between early-life family SEP and adult SEP (data not shown). Having a mother with high parity or having a younger or unmarried mother was associated
Table 1 Distribution of early-life characteristics in two generations from the Uppsala Multi-generational birth cohort, Sweden

\begin{tabular}{|c|c|c|c|c|c|}
\hline \multirow[b]{2}{*}{ Early-life characteristics } & \multicolumn{2}{|c|}{ Generation 1} & \multicolumn{2}{|c|}{ Generation 2} & \multirow[b]{2}{*}{$P$ value } \\
\hline & $\mathrm{N}$ & $\%$ & $\mathrm{~N}$ & $\%$ & \\
\hline \multicolumn{6}{|l|}{ Family socioeconomic position } \\
\hline High & 909 & 8.9 & 2247 & 37.1 & 0.001 \\
\hline Medium & 4213 & 41.2 & 1466 & 24.2 & \\
\hline Low & 5111 & 49.9 & 2342 & 38.7 & \\
\hline \multicolumn{6}{|l|}{ Mother's marital status } \\
\hline Married & 8514 & 83.2 & 5449 & 90.0 & 0.001 \\
\hline Unmarried & 1719 & 16.8 & 606 & 10.0 & \\
\hline \multicolumn{6}{|l|}{ Mother's parity } \\
\hline 1 & 3821 & 37.3 & 2823 & 46.6 & 0.001 \\
\hline 2 & 2490 & 24.3 & 1982 & 32.7 & \\
\hline$\geq 3$ & 3922 & 38.3 & 1250 & 20.6 & \\
\hline \multicolumn{6}{|l|}{ Birth weight (standardised) } \\
\hline SGA & 920 & 9.0 & 613 & 10.1 & 0.051 \\
\hline Normal & 8255 & 80.7 & 4838 & 79.9 & \\
\hline LGA & 1058 & 10.3 & 604 & 10.0 & \\
\hline \multicolumn{6}{|l|}{ Length of gestation } \\
\hline Preterm ( $\leq 36$ weeks) & 727 & 7.1 & 362 & 6.0 & 0.019 \\
\hline Term (37-41 weeks) & 8274 & 80.9 & 4970 & 82.1 & \\
\hline Post-term ( $\geq 42$ weeks) & 1232 & 12.0 & 723 & 11.9 & \\
\hline \multicolumn{6}{|l|}{ Multiplicity of birth } \\
\hline Singleton & 9971 & 97.4 & 5960 & 98.4 & 0.001 \\
\hline Twin/triplet & 262 & 2.6 & 95 & 1.6 & \\
\hline \multicolumn{6}{|l|}{ Mother's age (years) at birth } \\
\hline$<20$ & 458 & 4.5 & 510 & 8.4 & 0.001 \\
\hline $20-24$ & 2692 & 26.3 & 2093 & 34.6 & \\
\hline $25-29$ & 2913 & 28.5 & 2144 & 35.4 & \\
\hline $30-34$ & 2147 & 21.0 & 1044 & 17.2 & \\
\hline$\geq 35$ & 2023 & 19.8 & 264 & 4.4 & \\
\hline Total & 10233 & 100 & 6055 & 100 & \\
\hline
\end{tabular}

LGA, large-for-gestational age; SGA, small-for-gestational age.

with lower HISP scores in both generations. The association between mother's marital status and adult SEP in G1, however, attenuated when family SEP was accounted for. Being born smallfor-gestational age in G1 was associated with 2.9 point lower score $(95 \% \mathrm{CI}:-4.7$ to -1.2$)$ on the HISP scale as compared with being born with normal birth weight for gestational age. Controlling for the confounders hardly affected the strength of this association (table 2). The association did not reach statistical significance in G2, although a strong and statistically significant association was found in women ( $(\mathrm{s}:-3.5 ; 95 \% \mathrm{CI}$ : -5.3 to -1.7 , see also table 3 ). Preterm birth showed no association with HISP in either generation while post-term birth was associated with poorer HISP in both generations. Adjustment for the confounders resulted in a reduction of this association in G1 and a non-signification association in G2 (table 2).

The associations of adult SEP with standardised birth weight, gestational length, mother's parity and multiplicity of birth remained mostly stable over time, as evident from the exposuregeneration interactions in both minimally and multiply adjusted models. On the other hand, the association between family SEP and adult SEP substantially attenuated, with low versus high family SEP showing a decline in the HISP score by 15.8 percentage points (95\% CI: 13.3 to 18.3 ) in G2 compared with G1. Furthermore, the 
Distribution of the Hollingshead's Index by generation

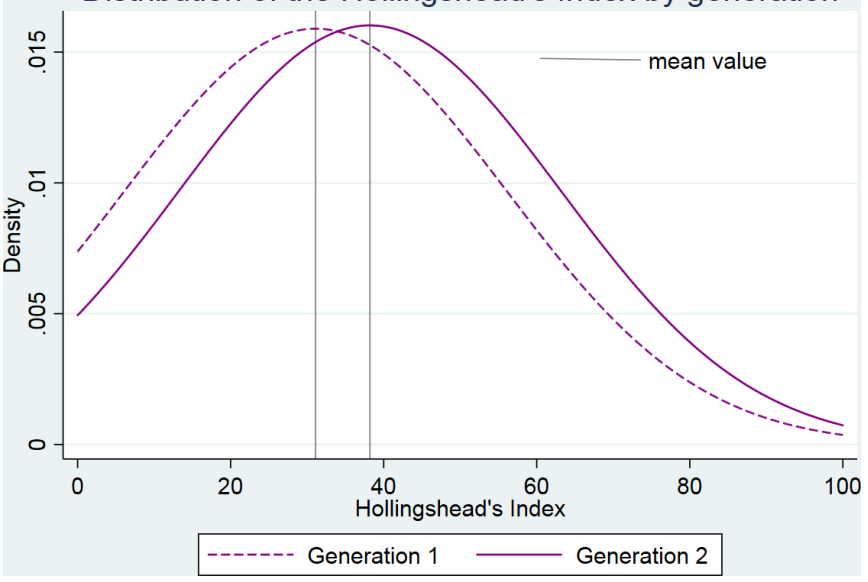

Figure 1 Density of the distribution of Hollingshead's Index of Social Position by generation.

associations of adult SEP with mother's marital status and mother's younger age at birth turned stronger in G2 (table 2).

Logistic regression analysis assessing HISP as a binary outcome revealed very similar trends (online supplementary table 2) with an exception of high parity showing an attenuated association. Similarly, the observed trends in the logistic regression models using education and occupation as separate outcomes (online supplementary table 3 and online supplementary table 4 , respectively) were largely consistent with the overall trends in the linear regression analysis, with a somewhat weaker association between SGA and educational attainment in G2 relative to G1.

No interactions were found between biological and social exposures with regard to the outcome. There was, however, an evidence of three-way interaction among family SEP, generation and gender ( $\mathrm{p}$ value for interaction 0.009). A similar three-way interaction was detected among mother's marital status, generation and gender ( $p$ value for interaction: 0.016). As shown in table 3 , the relative difference between low and high family SEP declined to greater extent in men ( $\beta^{\text {change }}$ : 18.9 ; 95\% CI: 15.6 to 22.3 ) than in women ( $\beta^{\text {change }}: 12.3 ; 95 \% \mathrm{CI}: 9.1$ to 15.7$)$. On the other hand, the association between mother's marital status and adult SEP became stronger among women while the same association among men remained unchanged.

Table 4 shows the associations linking offspring's adult SEP to maternal and paternal early-life characteristics. The results reveal that children's adult SEP was associated with parents' low family SEP at birth (ie, grandparental SEP) along both lines of parents ( $\beta^{\text {mother }}$ : $-10.3 ; 95 \% \mathrm{CI}:-16.0$ to -4.1 . $\beta^{\text {father }}:-7.9$; 95\% CI: -14.1 to -1.7$)$. The associations were attenuated when grandmothers' marital status was adjusted for (Model 2) and became considerably reduced with the adjustment for mothers'/ fathers' education, occupation and income (Model 3). On the other hand, the association between grandmothers' marital status and G2's adult SEP remained robust to the control for parents' family SEP (Model 2) and parental adult socioeconomic characteristics (Model 3) along the maternal lineage.

Compared with children whose fathers were born within the normal duration of gestation, children with fathers born preterm performed poorer as adults on the HISP scale $\left(\beta^{\text {father }}:-4.3\right.$; $95 \% \mathrm{CI}$ : -7.9 to -0.7$)$. This association remained significantly strong and robust even when the fathers' early-life conditions (Model 2) and adult socioeconomic circumstances (Model 3) were adjusted for $\left(\beta^{\text {father }}:-4.4 ; 95 \% \mathrm{CI}:-7.7\right.$ to -1.2$)$. Additional conditioning on children's birth weight, gestational age and multiplicity of birth did not explain the association either (data not shown).

The studied associations were not generally modified by the gender of children, except for father's family SEP which showed an association among male children only (data not shown).

\section{DISCUSSION \\ Main findings}

We investigated the connections between unfavourable conditions at birth and attainment of social class position in adult life across two Swedish generations. In line with previous research, we found that in both generations, individuals with poorer SEP in adulthood were more likely to have experienced social and biological disadvantages at birth, that is, had parents with lower social class, ${ }^{922}$ younger or unmarried mothers, ${ }^{22}$ families with relatively large number of older siblings, ${ }^{3435}$ restricted fetal growth ${ }^{91422}$ or were born post-term. ${ }^{14} 3637$ The trend analysis further suggests that the association between SEP of origin and SEP of destination became weaker over time while the associations between biological conditions at birth and adult SEP tended to be stable. We further demonstrated that the association between grandparental and grandchild SEPs was largely accounted for by parental adult socioeconomic conditions. On the other hand, paternal preterm birth remained associated with offspring's adult SEP irrespective of paternal adult socioeconomic circumstances.

\section{Interpretations}

The attenuation of the association between parental and own SEPs in the more recent generation suggests that Sweden has partially accomplished its political goal in establishing equal opportunity structures. This finding is unsurprising since the two generations under investigation had their upbringing and schooling in two different historical epochs, roughly before and after the period of sweeping social reforms in the late 1940s. ${ }^{17} 18$ We have further shown that men made longer strides over time than women when it comes to social mobility-an important gender difference which partly reflects the relatively low-skilled occupations held by women despite their increased participation in education and the labour force over time.

Whereas the effects of parental marital status and high parity on child outcomes are often attributed to socioeconomic disadvantages or the dilution of material household resources, ${ }^{38} 39$ our findings are not entirely in accord with this common explanation. Irrespective of parental SEP, this study shows strong birth order effects on own SEP in both generations and a stronger effect of mother's marital status in the younger generation. A stable trend of such effects across different birth cohorts were demonstrated in previous studies. ${ }^{22} 340$ Importantly, with the increased egalitarian social structure and reduced social stigma tied to births outside of marriages over time, the persistence of the effects in more advanced societies might involve a different mechanism. It is plausible that children having both parents or fewer siblings receive better quality environment for parent-child interaction which in turn favours their intellectual stimulation. ${ }^{41} 42$

Contrary to prior research that demonstrated cognitive and educational deficits in children born preterm, ${ }^{14} 4344$ we found no effect of preterm birth on adult SEP in either generation. However, reduced fetal growth and post-term birth emerged in this study as important early-life biological factors that impact on educational and occupational attainment. Importantly, our study provides little evidence of attenuation regarding the impact of biological disadvantages which seem to have a sustained influence on adult socioeconomic trajectories. 
Table 2 Generational differences in the associations between early-life characteristics and adult SEP measured by Hollingshead index, the Uppsala Multi-generational birth cohort, Sweden $(n=16$ 288)

\begin{tabular}{|c|c|c|c|c|c|c|}
\hline \multirow[b]{3}{*}{ Early-life characteristics* } & \multicolumn{3}{|l|}{ Model 1† } & \multicolumn{3}{|l|}{ Model 2‡ } \\
\hline & Generation 1 & Generation 2 & $\begin{array}{l}\text { Difference in } \\
\text { association }\end{array}$ & Generation 1 & Generation 2 & $\begin{array}{l}\text { Difference in } \\
\text { association }\end{array}$ \\
\hline & $B(95 \% \mathrm{Cl}) \S$ & $B(95 \% \mathrm{Cl}) \S$ & $\begin{array}{l}\beta^{\text {change }} \\
(95 \% \mathrm{CI}) \emptyset\end{array}$ & $ß(95 \% \mathrm{Cl}) \S$ & $ß(95 \% \mathrm{CI}) \S$ & $\begin{array}{l}\text { change } \\
(95 \% \mathrm{Cl}) \uparrow\end{array}$ \\
\hline \multicolumn{7}{|l|}{ Family SEP } \\
\hline High & Ref. & Ref. & Ref. & Ref. & Ref. & Ref. \\
\hline Medium & $\begin{array}{l}-24.9 \\
(-26.8 \text { to }-23.1)\end{array}$ & $\begin{array}{l}-10.8 \\
(-12.7 \text { to }-8.9)\end{array}$ & $\begin{array}{l}14.1 \\
(11.4 \text { to } 16.8)^{* *}\end{array}$ & $\begin{array}{l}-24.9 \\
(-26.8 \text { to }-23.0)\end{array}$ & $\begin{array}{l}-10.8 \\
(-12.8 \text { to }-8.9)\end{array}$ & $\begin{array}{l}14.1 \\
(11.4 \text { to } 16.7)^{* *}\end{array}$ \\
\hline Low & $\begin{array}{l}-30.3 \\
(-32.1 \text { to }-28.4)\end{array}$ & $\begin{array}{l}-13.7 \\
(-15.4 \text { to }-12.1)\end{array}$ & $\begin{array}{l}16.5 \\
(14.0 \text { to } 19.0)^{\text {** }}\end{array}$ & $\begin{array}{l}-29.4 \\
(-20.7 \text { to }-18.2)\end{array}$ & $\begin{array}{l}-13.6 \\
(-15.3 \text { to }-12.01)\end{array}$ & $\begin{array}{l}15.8 \\
(13.3 \text { to } 18.3)^{\text {** }}\end{array}$ \\
\hline \multicolumn{7}{|l|}{ Mother's marital status } \\
\hline Married & Ref. & Ref. & Ref. & Ref. & Ref. & Ref. \\
\hline Unmarried & $\begin{array}{l}-5.9 \\
(-7.2 \text { to }-4.7)\end{array}$ & $\begin{array}{l}-7.4 \\
(-9.4 \text { to }-5.3)\end{array}$ & $\begin{array}{l}-1.5 \\
(-3.8 \text { to } 1.0)^{* *}\end{array}$ & $\begin{array}{l}-1.0 \\
(-2.4 \text { to } 0.3)\end{array}$ & $\begin{array}{l}-6.9 \\
(-8.9 \text { to }-4.9)\end{array}$ & $\begin{array}{l}-5.9 \\
(-8.2 \text { to }-3.4)^{\text {** }}\end{array}$ \\
\hline \multicolumn{7}{|l|}{ Mother's parity } \\
\hline 1 & Ref. & Ref. & Ref. & Ref. & Ref. & Ref. \\
\hline 2 & $\begin{array}{l}-2.1 \\
(-3.3 \text { to }-0.9)\end{array}$ & $\begin{array}{l}-3.4 \\
(-4.7 \text { to }-2.1)\end{array}$ & $\begin{array}{l}-1.3 \\
(-3.0 \text { to } 0.5)\end{array}$ & $\begin{array}{l}-4.3 \\
(-5.5 \text { to }-3.1)\end{array}$ & $\begin{array}{l}-4.6 \\
(-5.9 \text { to }-3.3)\end{array}$ & $\begin{array}{l}-0.3 \\
(-2.0 \text { to } 1.4)\end{array}$ \\
\hline$\geq 3$ & $\begin{array}{l}-7.7 \\
(-8.8 \text { to }-6.6)\end{array}$ & $\begin{array}{l}-8.2 \\
(-9.9 \text { to }-6.5)\end{array}$ & $\begin{array}{l}-0.5 \\
(-2.6 \text { to } 1.5)\end{array}$ & $\begin{array}{l}-11.4 \\
(-12.7 \text { to }-10.2)\end{array}$ & $\begin{array}{l}-9.6 \\
(-11.3 \text { to }-7.9)\end{array}$ & $\begin{array}{l}1.8 \\
(-0.2 \text { to } 3.8)\end{array}$ \\
\hline \multicolumn{7}{|c|}{ Birth weight (standardised) } \\
\hline SGA & $\begin{array}{l}-2.9 \\
(-4.7 \text { to }-1.2)\end{array}$ & $\begin{array}{l}-1.6^{* *} \\
(-3.8 \text { to } 0.5)\end{array}$ & $\begin{array}{l}1.3 \\
(-1.4 \text { to } 4.1)\end{array}$ & $\begin{array}{l}-3.00 \\
(-4.6 \text { to }-1.4)\end{array}$ & $\begin{array}{l}-1.5^{* *} \\
(-3.6 \text { to } 0.5)\end{array}$ & $\begin{array}{l}1.5 \\
(-1.1 \text { to } 4.1)\end{array}$ \\
\hline Normal & Ref. & Ref. & Ref. & Ref. & Ref. & Ref. \\
\hline LGA & $\begin{array}{l}-0.1 \\
(-2.6 \text { to } 0.7)\end{array}$ & $\begin{array}{l}1.4 \\
(-0.8 \text { to } 3.6)\end{array}$ & $\begin{array}{l}2.4 \\
(-0.3 \text { to } 5.2)\end{array}$ & $\begin{array}{l}-0.1 \\
(-1.6 \text { to } 1.5)\end{array}$ & $\begin{array}{l}2.5 \\
(0.4 \text { to } 4.6)\end{array}$ & $\begin{array}{l}2.6 \\
(-0.0 \text { to } 5.2)\end{array}$ \\
\hline \multicolumn{7}{|l|}{ Length of gestation } \\
\hline Preterm ( $\leq 36$ weeks) & $\begin{array}{l}-1.2 \\
(-3.1 \text { to } 0.8)\end{array}$ & $\begin{array}{l}-1.6 \\
(-4.5 \text { to } 1.3)\end{array}$ & $\begin{array}{l}-0.4 \\
(-3.91 \text { to } 3.07)\end{array}$ & $\begin{array}{l}-0.1 \\
(-2.0 \text { to } 1.7)\end{array}$ & $\begin{array}{l}-1.3 \\
(-4.1 \text { to } 1.4)\end{array}$ & $\begin{array}{l}-1.2 \\
(-4.4 \text { to } 2.1)\end{array}$ \\
\hline Term (37-41 weeks) & Ref. & Ref. & Ref. & Ref. & Ref. & Ref. \\
\hline Post-term ( $\geq 42$ weeks) & $\begin{array}{l}-3.1 \\
(-4.6 \text { to }-1.6)\end{array}$ & $\begin{array}{l}-2.6 \\
(-4.6 \text { to }-0.4)\end{array}$ & $\begin{array}{l}0.5 \\
(-2.03 \text { to } 2.96)\end{array}$ & $\begin{array}{l}-2.3 \\
(-3.7 \text { to }-0.9)\end{array}$ & $\begin{array}{l}-1.7 \\
(-3.5 \text { to } 0.2)\end{array}$ & $\begin{array}{l}0.6 \\
(-1.7 \text { to } 2.9)\end{array}$ \\
\hline \multicolumn{7}{|l|}{ Multiplicity of birth } \\
\hline Singleton & Ref. & Ref. & Ref. & Ref. & Ref. & Ref. \\
\hline Twin/triplet & $\begin{array}{l}-2.8 \\
(-6.6 \text { to } 0.9)\end{array}$ & $\begin{array}{l}-6.0 \\
(-11.6 \text { to }-0.4)\end{array}$ & $\begin{array}{l}-3.2 \\
\text { (-9.9 to } 3.5)\end{array}$ & $\begin{array}{l}-2.7 \\
(-6.1 \text { to } 0.7)\end{array}$ & $\begin{array}{l}-4.5 \\
(-10.1 \text { to } 1.1)\end{array}$ & $\begin{array}{l}-1.8 \\
(-8.3 \text { to } 4.7)\end{array}$ \\
\hline \multicolumn{7}{|c|}{ Mother's age (years) at birth } \\
\hline$<20$ & $\begin{array}{l}-4.6 \\
(-6.9 \text { to }-2.2)\end{array}$ & $\begin{array}{l}-7.1 \\
(-9.5 \text { to }-4.7)\end{array}$ & $\begin{array}{l}-2.5 \\
(-5.9 \text { to } 0.8)\end{array}$ & $\begin{array}{l}0.3 \\
(-2.1 \text { to } 2.7)\end{array}$ & $\begin{array}{l}-5.7 \\
(-8.1 \text { to }-3.3)\end{array}$ & $\begin{array}{l}-6.0 \\
(-9.3 \text { to }-2.7)\end{array}$ \\
\hline $20-24$ & $\begin{array}{l}-2.9 \\
(-4.3 \text { to }-1.6)\end{array}$ & $\begin{array}{l}-3.7 \\
(-5.3 \text { to }-2.2)\end{array}$ & $\begin{array}{l}-0.8 \\
(-2.8 \text { to } 1.2)\end{array}$ & $\begin{array}{l}-0.5 \\
(-1.8 \text { to }-0.8)\end{array}$ & $\begin{array}{l}-2.9 \\
(-4.4 \text { to }-1.5)\end{array}$ & $\begin{array}{l}-2.4 \\
(-4.2 \text { to }-0.5)\end{array}$ \\
\hline $25-29$ & Ref. & Ref. & Ref. & Ref. & Ref. & Ref. \\
\hline $30-34$ & $\begin{array}{l}1.0 \\
(-0.4 \text { to } 2.5)\end{array}$ & $\begin{array}{l}0.7 \\
(-1.2 \text { to } 2.5)\end{array}$ & $\begin{array}{l}-0.3 \\
(-2.7 \text { to } 2.0)\end{array}$ & $\begin{array}{l}0.2 \\
(-1.1 \text { to } 1.5)\end{array}$ & $\begin{array}{l}0.8 \\
(-1.0 \text { to } 2.6)\end{array}$ & $\begin{array}{l}0.6 \\
(-1.7 \text { to } 2.8)\end{array}$ \\
\hline$\geq 35$ & $\begin{array}{l}-1.7 \\
(-3.2 \text { to }-0.2)\end{array}$ & $\begin{array}{l}-1.0 \\
(-4.3 \text { to } 2.4)\end{array}$ & $\begin{array}{l}0.7 \\
(-2.9 \text { to } 4.4)\end{array}$ & $\begin{array}{l}-2.6 \\
(-4.0 \text { to }-1.1)\end{array}$ & $\begin{array}{l}-0.9 \\
(-4.1 \text { to } 2.4)\end{array}$ & $\begin{array}{l}1.7 \\
(-1.8 \text { to } 5.2)\end{array}$ \\
\hline
\end{tabular}

Bold typeface indicates statistical significance $(p<0.05)$.

*Each exposure represents a separate linear regression model.

tModel 1 statistically adjusted for year of birth (gender was also adjusted for to estimate the effect of length of gestation).

¥Model 2 additionally adjusted for different sets of confounders for different exposures. The associations with family SEP and mother's marital status were estimated by adjusting for each other. The association with mother's parity was estimated by adjusting for family SEP, multiplicity of birth, mother's marital status and mother's age at child birth. The associations with standardised birth weight, length of gestation and multiplicity of births were estimated by adjusting for all exposures. The association with mother's age at birth was adjusted for family SEP and mother's marital status. An exposure* generation interaction term was fitted in all models to assess if the associations vary by generation. Since a significant interaction between family SEP and generation was detected in Model 1, this interaction was adjusted for in Model 2 when appropriate.

§Obtained in post-estimation from the fitted linear regression models.

ๆObtained from linear regression models by fitting an interaction term of exposure* generation.

**Estimates modified by gender: $p$ value for family SEP* generation*gender $=0.009 ; p$ value for marital status* generation*gender $=0.016$. See also table 3 .

$B$, beta coefficient; LGA, large-for-gestational age; Ref., reference group; SEP, socioeconomic position; SGA, small-for-gestational age. 
Table 3 Generational differences in the gender-modified associations between early-life characteristics and adult SEP measured by Hollingshead index, the Uppsala Multi-generational birth cohort, Sweden

\begin{tabular}{|c|c|c|c|c|c|c|}
\hline \multirow[b]{3}{*}{ Early-life social characteristics* } & \multicolumn{3}{|l|}{ Men $(n=8513)$} & \multicolumn{3}{|l|}{ Women $(n=7775)$} \\
\hline & Generation 1 & Generation 2 & $\begin{array}{l}\text { Difference in } \\
\text { association }\end{array}$ & Generation 1 & Generation 2 & $\begin{array}{l}\text { Difference in } \\
\text { association }\end{array}$ \\
\hline & $B(95 \% \mathrm{Cl}) \dagger$ & $B(95 \% \mathrm{Cl}) \dagger$ & $\begin{array}{l}\beta^{\text {change }} \\
(95 \% \mathrm{Cl}) \ddagger\end{array}$ & $B(95 \% \mathrm{Cl}) \dagger$ & $B(95 \% \mathrm{Cl}) \dagger$ & $\begin{array}{l}\beta^{\text {change }} \\
(95 \% \mathrm{Cl}) \ddagger\end{array}$ \\
\hline \multicolumn{7}{|l|}{ Family SEP } \\
\hline High & Ref. & Ref. & Ref. & Ref. & Ref. & Ref. \\
\hline Low & $\begin{array}{l}-33.8 \\
(-36.4 \text { to }-31.2)\end{array}$ & $\begin{array}{l}-14.9 \\
(-17.0 \text { to }-12.7)\end{array}$ & $\begin{array}{l}18.9 \\
\text { (15.6 to 22.3) }\end{array}$ & $\begin{array}{l}-24.7 \\
(-27.2 \text { to }-22.3)\end{array}$ & $\begin{array}{l}-12.4 \\
(-14.6 \text { to }-10.1)\end{array}$ & $\begin{array}{l}12.3 \\
\text { (9.1 to } 15.7)\end{array}$ \\
\hline \multicolumn{7}{|l|}{ Mother's marital status } \\
\hline Married & Ref. & Ref. & Ref. & Ref. & Ref. & Ref. \\
\hline Unmarried & $\begin{array}{l}-3.8 \\
(-5.7 \text { to }-1.9)\end{array}$ & $\begin{array}{l}-5.2 \\
(-8.0 \text { to }-2.4)\end{array}$ & $\begin{array}{l}-1.4 \\
\text { (-4.7 to } 2.0)\end{array}$ & $\begin{array}{l}-1.2 \\
(-2.9 \text { to } 0.6)\end{array}$ & $\begin{array}{l}-8.1 \\
(-11.0 \text { to }-5.2)\end{array}$ & $\begin{array}{l}-6.9 \\
(-10.3 \text { to }-3.6)\end{array}$ \\
\hline Normal & Ref. & Ref. & Ref. & Ref. & Ref. & Ref. \\
\hline LGA & $\begin{array}{l}1.1 \\
(-1.1 \text { to } 3.2)\end{array}$ & $\begin{array}{l}3.1 \\
(0.2 \text { to } 6.0)\end{array}$ & $\begin{array}{l}2.0 \\
(-1.6 \text { to } 5.6)\end{array}$ & $\begin{array}{l}-1.2 \\
(-3.2 \text { to } 0.9)\end{array}$ & $\begin{array}{l}2.1 \\
(-0.9 \text { to } 5.0)\end{array}$ & $\begin{array}{l}3.3 \\
(-0.4 \text { to } 6.8)\end{array}$ \\
\hline
\end{tabular}

Bold typeface indicates statistical significance $(p<0.05)$.

*Each exposure represents a separate linear regression model. The association with family SEP was adjusted for year of birth and mother's marital status. The association with mother's marital status was adjusted for year of birth, family SEP and family socioeconomic position* generation. The association with standardised birth weight was adjusted for year of birth, mother's age at birth, mother's parity, length of gestation, multiplicity of birth, family SEP, mother's marital status, and family SEP*generation.

tObtained in post-estimation from the fitted linear regression models.

¥0btained from linear regression models by fitting an interaction term of exposure* generation.

B, beta coefficient; LGA, large-for-gestational age; Ref., reference group; SEP, socioeconomic position; SGA, small-for-gestational age.

The empirical literature to compare this trend with is scarce. A Swedish study ${ }^{14}$ conducted among the school children born 1973 through 1994 suggests a persistent effect of reduced fetal growth on later school performance with no indication of effect modification by time period. Both reduced fetal growth and postterm birth are known as markers of nutritional deficiencies and unhealthy uterine environments that may impair fetal brain and body development. ${ }^{45-47}$ This, in turn, may lead to child's poorer cognitive functioning, ${ }^{48}$ behavioural and emotional problems, ${ }^{49}$ and other neurological or developmental disorders ${ }^{50}$ compromising later intellectual performance and entry into the labour market. The observed stability of the impact of biological disadvantages over time, therefore, points to the urgency of undertaking further research for an improved understanding of the health selection processes and for informing specific policies and interventions supporting the biologically disadvantaged children.

In keeping with previous transgenerational research, ${ }^{22-27}$ this study further suggests that the effects of early-life characteristics are likely to persist through several generations. The social exposures in this study (ie, family SEP in childhood and mother's marital status at birth) span over three generations-grandparents, parents and children-allowing us to assess the multigenerational effect of grandparent's SEP and grandmother's marital status on grandchildren's adult SEP. The effects of grandparent's SEP and the grandmother's marital status were found to be transmitted to their grandchildren along both maternal and paternal lines. Partly contradicting previous studies that reported a direct effect of grandparent's SEP on the SEP of grandchildren, ${ }^{23-25}$ our study found only an indirect effect operating through parental education, occupation and income.

An unexpected finding is the father's preterm birth exerting a strong effect on offspring's adult SEP. Intriguingly, this effect is explained neither by paternal adult socioeconomic circumstances nor by offspring's health conditions at birth. This persisting intergenerational influence might theoretically be attributed in part to the increased susceptibility of the male fetuses to maternal stress during pregnancy, ${ }^{12}$ a biological disadvantage likely to be passed on to the succeeding generation via genetic or epigenetic pathways $^{1251}$ and may include mechanisms involving personality traits or cognitive function ${ }^{5152}$ of the offspring of preterm fathers. Further research is needed to replicate this novel finding in other settings and explore its mechanisms.

\section{Strengths and limitations}

We accounted for a broad set of social, demographic and/ or biological factors when assessing the effect of a particular exposure on the socioeconomic outcome, although residual confounding by unobserved family traits could remain. A merit of the paper is the capturing of two most important dimensions of socioeconomic stratification-education and occupationinto a composite outcome measure. Previous studies applying the Hollingshead's index in the Swedish context found it to be a good discriminator of mortality and other health outcomes. ${ }^{32} 33$ Finally, the availability of comparable early-life biological indicators across two generations allowed this study to document systematically, for the first time, the historical comparison of the established associations in a changing societal context. At the same time, it extends the current literature by generating new evidence on the lineage-specific reproduction of early-life disadvantages across two generations.

While G1 was broadly representative of all Swedish births in terms of infant mortality and fertility during the respective historical period, ${ }^{53}$ the $\mathrm{G} 2$ participants include children born in 
Table 4 Associations between maternal and paternal early-life characteristics and children's adult SEP measured by Hollingshead Index, the Uppsala Multi-generational Birth Cohort, Sweden

\begin{tabular}{|c|c|c|c|c|c|c|}
\hline \multirow[b]{3}{*}{ Parents' early-life characteristics* } & \multicolumn{3}{|c|}{ Mothers $(n=3192)$} & \multicolumn{3}{|c|}{ Fathers $(n=3126)$} \\
\hline & Model 1† & Model $2 \ddagger$ & Model $3 \S$ & Model 1† & Model 2‡ & Model $3 \S$ \\
\hline & $B(95 \% \mathrm{Cl})$ & $B(95 \% \mathrm{Cl})$ & $B(95 \% \mathrm{Cl})$ & $B(95 \% \mathrm{Cl})$ & $B(95 \% \mathrm{Cl})$ & $B(95 \% \mathrm{Cl})$ \\
\hline \multicolumn{7}{|l|}{ Family SEP } \\
\hline High & Ref. & Ref. & Ref. & Ref. & Ref. & Ref. \\
\hline Medium & $\begin{array}{l}-6.9 \\
(-12.9 \text { to }-0.9)\end{array}$ & $\begin{array}{l}-6.8 \\
(-12.8 \text { to }-0.8)\end{array}$ & $\begin{array}{l}-0.9 \\
(-6.1 \text { to } 4.3)\end{array}$ & $\begin{array}{l}-6.0 \\
(-12.2 \text { to } 0.2)\end{array}$ & $\begin{array}{l}-6.0 \\
(-12.2 \text { to } 0.2)\end{array}$ & $\begin{array}{l}-3.7 \\
(-1.1 \text { to } 8.5)\end{array}$ \\
\hline Low & $\begin{array}{l}-10.0 \\
(-16.0 \text { to }-4.1)\end{array}$ & $\begin{array}{l}-9.0 \\
(-15.0 \text { to }-2.9)\end{array}$ & $\begin{array}{l}-2.2 \\
(-7.5 \text { to } 3.0)\end{array}$ & $\begin{array}{l}-8.5 \\
(-14.6 \text { to }-2.3)\end{array}$ & $\begin{array}{l}-7.9 \\
(-14.1 \text { to }-1.7)\end{array}$ & $\begin{array}{l}-2.7 \\
(-2.0 \text { to } 7.5)\end{array}$ \\
\hline \multicolumn{7}{|l|}{ Mother's marital status } \\
\hline Married & Ref. & Ref. & Ref. & Ref. & Ref. & Ref. \\
\hline Unmarried & $\begin{array}{l}-4.9 \\
(-7.7 \text { to }-2.1)\end{array}$ & $\begin{array}{l}-3.7 \\
(-6.6 \text { to }-0.8)\end{array}$ & $\begin{array}{l}-2.8 \\
(-5.4 \text { to }-0.1)\end{array}$ & $\begin{array}{l}-3.3 \\
(-6.2 \text { to }-0.4)\end{array}$ & $\begin{array}{l}-2.1 \\
(-5.1 \text { to } 0.9)\end{array}$ & $\begin{array}{l}1.9 \\
(-4.6 \text { to } 0.9)\end{array}$ \\
\hline \multicolumn{7}{|l|}{ Mother's parity } \\
\hline 1 & Ref. & Ref. & Ref. & Ref. & Ref. & Ref. \\
\hline 2 & $\begin{array}{l}-1.3 \\
(-1.6 \text { to } 4.2)\end{array}$ & $\begin{array}{l}-0.0 \\
(-3.1 \text { to } 3.0)\end{array}$ & $\begin{array}{l}2.2 \\
(-0.6 \text { to } 5.0)\end{array}$ & $\begin{array}{l}-0.7 \\
(-3.5 \text { to } 2.0)\end{array}$ & $\begin{array}{l}-2.3 \\
(-5.2 \text { to } 0.5)\end{array}$ & $\begin{array}{l}-1.6 \\
(-4.2 \text { to } 1.0)\end{array}$ \\
\hline$\geq 3$ & $\begin{array}{l}-1.1 \\
(-3.6 \text { to } 1.4)\end{array}$ & $\begin{array}{l}-3.7 \\
(-6.7 \text { to }-0.8)\end{array}$ & $\begin{array}{l}-0.7 \\
(-3.4 \text { to } 2.1)\end{array}$ & $\begin{array}{l}-2.2 \\
(-4.6 \text { to } 0.2)\end{array}$ & $\begin{array}{l}-4.7 \\
(-7.6 \text { to }-1.7)\end{array}$ & $\begin{array}{l}-1.7 \\
(-4.5 \text { to } 1.0)\end{array}$ \\
\hline \multicolumn{7}{|l|}{ Birth weight (standardised) } \\
\hline SGA & $\begin{array}{l}-3.2 \\
(-6.9 \text { to } 0.4)\end{array}$ & $\begin{array}{l}-3.9 \\
(-7.8 \text { to } 0.0)\end{array}$ & $\begin{array}{l}-2.6 \\
(-6.0 \text { to } 0.9)\end{array}$ & $\begin{array}{l}-0.4 \\
(-4.4 \text { to } 3.5)\end{array}$ & $\begin{array}{l}-0.0 \\
(-3.8 \text { to } 3.8)\end{array}$ & $\begin{array}{l}0.1 \\
(-2.4 \text { to } 4.3)\end{array}$ \\
\hline Normal & Ref. & Ref. & Ref. & Ref. & Ref. & Ref. \\
\hline LGA & $\begin{array}{l}-0.85 \\
(-4.4 \text { to } 2.7)\end{array}$ & $\begin{array}{l}-0.7 \\
(-4.3 \text { to } 2.8)\end{array}$ & $\begin{array}{l}-1.2 \\
(-4.6 \text { to } 2.2)\end{array}$ & $\begin{array}{l}1.3 \\
(-2.0 \text { to } 4.6)\end{array}$ & $\begin{array}{l}1.6 \\
(-1.7 \text { to } 5.0)\end{array}$ & $\begin{array}{l}1.1 \\
(-2.0 \text { to } 4.3)\end{array}$ \\
\hline \multicolumn{7}{|l|}{ Length of gestation } \\
\hline Preterm ( $\leq 36$ weeks) & $\begin{array}{l}-1.1 \\
(-5.0 \text { to } 2.8)\end{array}$ & $\begin{array}{l}-0.8 \\
(-4.9 \text { to } 3.2)\end{array}$ & $\begin{array}{l}-1.2 \\
(-4.8 \text { to } 2.4)\end{array}$ & $\begin{array}{l}-4.3 \\
(-7.9 \text { to }-0.7)\end{array}$ & $\begin{array}{l}-3.8 \\
(-7.5 \text { to }-0.1)\end{array}$ & $\begin{array}{l}-4.4 \\
(-7.7 \text { to }-1.2)\end{array}$ \\
\hline Term (37-41 weeks) & Ref. & Ref. & Ref. & Ref. & Ref. & Ref. \\
\hline Post-term ( $\geq 42$ weeks) & $\begin{array}{l}-1.1 \\
(-4.5 \text { to } 2.2)\end{array}$ & $\begin{array}{l}-0.7 \\
(-4.0 \text { to } 2.5)\end{array}$ & $\begin{array}{l}1.0 \\
(-2.0 \text { to } 4.0)\end{array}$ & $\begin{array}{l}-1.2 \\
(-4.6 \text { to } 2.1)\end{array}$ & $\begin{array}{l}-0.9 \\
(-4.2 \text { to } 2.3)\end{array}$ & $\begin{array}{l}-0.1 \\
(-3.2 \text { to } 3.0)\end{array}$ \\
\hline \multicolumn{7}{|l|}{ Multiplicity of birth } \\
\hline Singleton & Ref. & Ref. & Ref. & Ref. & Ref. & Ref. \\
\hline Twin/triplet & $\begin{array}{l}-2.8 \\
(-9.6 \text { to } 4.0)\end{array}$ & $\begin{array}{l}-3.1 \\
(-10.2 \text { to } 4.0)\end{array}$ & $\begin{array}{l}-1.2 \\
(-7.2 \text { to } 4.9)\end{array}$ & $\begin{array}{l}-6.3 \\
(-15.6 \text { to } 2.9)\end{array}$ & $\begin{array}{l}-6.90 \\
(-14.9 \text { to } 3.0)\end{array}$ & $\begin{array}{l}-5.2 \\
(-13.2 \text { to } 2.8)\end{array}$ \\
\hline \multicolumn{7}{|l|}{ Mother's age (years) at birth } \\
\hline$<20$ & $\begin{array}{l}-0.1 \\
(-4.5 \text { to } 4.4)\end{array}$ & $\begin{array}{l}2.9 \\
(-1.8 \text { to } 7.7)\end{array}$ & $\begin{array}{l}3.2 \\
(-1.3 \text { to } 7.8)\end{array}$ & $\begin{array}{l}-5.4 \\
(-10.7 \text { to }-0.0)\end{array}$ & $\begin{array}{l}-3.6 \\
(-9.4 \text { to } 2.1)\end{array}$ & $\begin{array}{l}-2.4 \\
(-7.8 \text { to } 3.0)\end{array}$ \\
\hline $20-24$ & $\begin{array}{l}-1.5 \\
(-4.4 \text { to } 1.5)\end{array}$ & $\begin{array}{l}-0.2 \\
(-3.2 \text { to } 2.8)\end{array}$ & $\begin{array}{l}0.7 \\
(-2.0 \text { to } 3.4)\end{array}$ & $\begin{array}{l}-2.6 \\
(-5.3 \text { to } 0.1)\end{array}$ & $\begin{array}{l}-1.9 \\
(-4.6 \text { to } 0.9)\end{array}$ & $\begin{array}{l}-1.8 \\
(-4.4 \text { to } 0.7)\end{array}$ \\
\hline $25-29$ & Ref. & Ref. & Ref. & Ref. & & Ref. \\
\hline $30-34$ & $\begin{array}{l}1.5 \\
(-1.7 \text { to } 4.7)\end{array}$ & $\begin{array}{l}1.1 \\
(-2.1 \text { to } 4.2)\end{array}$ & $\begin{array}{l}1.6 \\
(-1.2 \text { to } 4.5)\end{array}$ & $\begin{array}{l}-0.2 \\
(-3.1 \text { to } 2.7)\end{array}$ & $\begin{array}{l}-0.5 \\
(-3.4 \text { to } 2.3)\end{array}$ & $\begin{array}{l}-0.7 \\
(-3.3 \text { to } 1.8)\end{array}$ \\
\hline$\geq 35$ & $\begin{array}{l}0.4 \\
(-2.7 \text { to } 3.4)\end{array}$ & $\begin{array}{l}-0.2 \\
(-3.3 \text { to } 2.9)\end{array}$ & $\begin{array}{l}0.9 \\
(-1.8 \text { to } 3.6)\end{array}$ & $\begin{array}{l}-2.5 \\
(-5.5 \text { to } 0.6)\end{array}$ & $\begin{array}{l}-3.1 \\
(-6.2 \text { to } 0.0)\end{array}$ & $\begin{array}{l}-2.3 \\
(-5.1 \text { to } 0.4)\end{array}$ \\
\hline
\end{tabular}

Bold typeface indicates statistical significance $(p<0.05)$.

*Each exposure represents a separate linear regression model.

tModel 1 adjusted for mother's/father's respective year of birth and child's year of birth.

¥Model 2 additionally adjusted for different sets of confounders for different exposures. The associations with parent's family SEP and mother's marital status were estimated by adjusting for each other. The association with mother's parity was estimated by adjusting for mother's/father's respective early-life family SEP, multiplicity of birth, mother's marital status and mother's age at birth. The associations with parental birth weight, length of gestation and multiplicity of births were estimated by adjusting for all exposures. The association with parent's mother's age at birth was adjusted for the parent's early-life family SEP and mother's marital status.

§Model 3 further adjusted for mother's/father's respective education, occupation and income.

B, beta coefficient; LGA, large-for-gestational age; Ref., reference group; SEP, socioeconomic position; SGA, small-for-gestational age.

the Uppsala region only. To the extent that being born in versus outside Uppsala is correlated with both early-life characteristics and adult SEP (online supplementary table 6), the results might suffer from selection bias. A sensitivity analysis of the association between early and adult SEPs in the entire G2 population indicates a likely underestimation of the social inequalities in the current study. Another limitation is that while G1 were born in a 15 -year historical period (1915-1929), G2 was composed by people born across 29 years (1932-1960). However, we obtained very consistent 
results when performing sensitivity analysis on a restricted G2 sample born during 1945-1960 (online supplementary table 5).

\section{CONCLUSIONS}

The role of parental social class on own socioeconomic achievement substantially declined over historical time, whereas the biological conditions around the time of birth continue to take their toll. Hence, more effective policies and interventions specifically designed for biologically disadvantaged offspring are warranted. This requires further research to pay more attention to health in early life and better document and understand the health selection mechanisms. The fact that the early-life SEP remains strongly associated with adult SEP in the later-born generation is a cause for concern and highlights the importance of continued efforts to minimise the rich-poor gap from the very start of life.

\section{What is already known on this subject}

- The associations of social and health conditions at birth with socioeconomic outcomes in adult life have been well documented. Whether the established associations have become stronger or weaker over historical time remains to be known.

- Offspring's adult socioeconomic position (SEP) is shown to be associated with parents' early-life socioeconomic conditions but little is known about its association with parent's earlylife biological conditions.

\section{What this study adds}

- The current study systematically examines the associations of both social and biological conditions at birth with the attainment of adult SEP across two generations of Swedish families.

- The association between early-life and adult SEPs has become weaker, but still clearly evident, in the more recent generation while the associations between biological conditions at birth and adult SEP remain unchanged.

- The early-life SEP of both fathers and mothers was found to affect offspring's adult SEP mostly via parental adult socioeconomic circumstances.

- Father's preterm birth remained associated with offspring's adult SEP independent of father's adult circumstances.

- The study findings highlight the importance of effective policies and interventions supporting the offspring who are disadvantaged at birth, either socially or biologically.

Correction notice This artice has been corrected since it first published. Note that there is a discrepancy between the print version and the online version - this online version should be considered the final version of record.

Acknowledgements The authors would like to thank Arijeta Makolli for data collection and data entry and Dr Anna Goodman for assistance in data management and advice on analysis.

Contributors All authors contributed to the conception and design of the study. MZH performed statistical analyses and drafted the manuscript. IK directed the implementation of the study. Both JB and IK provided advice on the analytic strategy. All authors critically revised and edited the manuscript and approved the final version.

Funding The study was supported by grants from the European Union's Horizon 2020 research and innovation programme under grant agreement № 635316 (ATHLOS project) and from the Swedish Research Council (Projects No 2013-5104 and 2013-5474).

Competing interests None declared.

\section{Patient consent for publication Not required.}

Ethics approval The study was approved by the Regional Ethics Committee in Stockholm (Approval number: 03-117, 04-944T, 2009/1115-32, 2009/1830-32 and 2014/2058-31/5).

Provenance and peer review Not commissioned; externally peer reviewed.

Data availability statement Data are not publicly available. However, deidentified data can be obtained on a reasonable request to llona Koupil.

Open access This is an open access article distributed in accordance with the Creative Commons Attribution Non Commercial (CC BY-NC 4.0) license, which permits others to distribute, remix, adapt, build upon this work non-commercially, and license their derivative works on different terms, provided the original work is properly cited, appropriate credit is given, any changes made indicated, and the use is non-commercial. See: http://creativecommons.org/licenses/by-nc/4.0/.

\section{ORCID iDs}

Muhammad Zakir Hossin http://orcid.org/0000-0002-9078-419X

Jonas Björk http://orcid.org/0000-0003-1883-2000

Ilona Koupil http://orcid.org/0000-0002-7034-1922

\section{REFERENCES}

1 Mackenbach JP. The persistence of health inequalities in modern welfare states: the explanation of a paradox. Soc Sci Med 2012;75:761-9.

2 Mackenbach JP. Persistence of social inequalities in modern welfare states: explanation of a paradox. Scand J Public Health 2017;45:113-20.

3 Bambra C. Health inequalities and welfare state regimes: theoretical insights on a public health 'puzzle'. J Epidemiol Community Health 2011;65:740-5.

4 Almond D, Currie J. Killing me softly: the fetal origins hypothesis. J Econ Perspect 2011;25:153-72

5 Palloni A. Reproducing inequalities: luck, wallets, and the enduring effects of childhood health. Demography 2006;43:587-615.

6 Barker DJP. The developmental origins of adult disease. J Am Coll Nutr 2004;23:588S-95.

7 Kuh D, Ben-Shlomo Y. A life course approach to chronic disease epidemiology. Oxford University Press: Oxford, 2004.

8 Koupil I, Goodman A. Health equity : a lifecourse approach, 2011.

9 Palloni A, Milesi C, White RG, et al. Early childhood health, reproduction of economic inequalities and the persistence of health and mortality differentials. Soc Sci Med 2009:68:1574-82.

10 Graham H, Power C. Childhood disadvantage and health inequalities: a framework for policy based on lifecourse research. Child Care Heal Dev 2004;30:671-8.

11 Barker DJP. The fetal and infant origins of disease. Eur J Clin Invest 1995;25:457-63.

12 Glover V. Maternal stress during pregnancy and infant and child outcomes. In: The Oxford handbook of perinatal psychology, 2016: 268-83.

13 Case A, Fertig A, Paxson C. The lasting impact of childhood health and circumstance. J Health Econ 2005;24:365-89.

14 Abel K, Heuvelman H, Wicks S, et al. Gestational age at birth and academic performance: population-based cohort study. Int J Epidemiol 2016;88:dyw284.

15 Smith JP. The impact of childhood health on adult labor market outcomes. Rev Econ Stat 2009;91:478-89.

16 Pakpahan $\mathrm{E}$, Hoffmann $\mathrm{R}$, Kröger $\mathrm{H}$. The long arm of childhood circumstances on health in old age: evidence from SHARELIFE. Adv Life Course Res 2017;31:1-10.

17 Valocchi S. The origins of the Swedish welfare state: a class analysis of the state and welfare politics. Soc Prob/ 1992:39:189-200.

18 Holmlund H. A researcher's guide to the Swedish compulsory school reform. No. 87 London: Centre for the Economics of Education, London School of Economics and Political Science, 2008.

19 Modin B. Born out of wedlock and never married_-it breaks a man's heart. Soc Sci Med 2003;57:487-501.

20 Krieger N, Alegría M, Almeida-Filho N, et al. Who, and what, causes health inequities? reflections on emerging debates from an exploratory Latin American/North American workshop. J Epidemiol Community Health 2010;64:747-9.

21 Beckfield J, Krieger N. Epi + demos + cracy: linking political systems and priorities to the magnitude of health inequities--evidence, gaps, and a research agenda. Epidemiol Rev 2009:31:152-77

22 Goodman A, Gisselmann M, Koupil I. Birth characteristics and early-life social characteristics predict unequal educational outcomes across the life course and across generations. Longit Life Course Stud 2010;1:317-38.

23 Dribe M, Helgertz J. The lasting impact of grandfathers: class, occupational status, and earnings over three generations in Sweden 1815-2011. J Econ Hist 2016;76:969-1000.

24 Chan TW, Boliver V. The grandparents effect in social mobility: evidence from British birth cohort studies. Am Sociol Rev 2013;78:662-78.

25 Lindahl M, Palme M, Massih SS, et al. Long-Term intergenerational persistence of human capital. J Hum Resour 2015;50:1-33. 
26 Vauhkonen T, Kallio J, Kauppinen TM, et al. Intergenerational accumulation of social disadvantages across generations in young adulthood. Res Soc Stratif Mobil 2017;48:42-52.

27 Anderson L, Sheppard P, Monden C. Grandparent effects on educational outcomes: a systematic review. Socio/ Sci 2018;5:114-42.

28 Koupil I. The Uppsala studies on developmental origins of health and disease. J Intern Med 2007;261:426-36.

29 Hollingshead AB. Two factor index of social position. New Haven, Connecticut: Yale University, Department of Sociology, 1957.

30 Hollingshead AB, Redlich FC. Social class and mental illness: a community study. New York: Wiley, 1958.

31 Sweden S. Reports on statistical co-ordination 1982:4. Swedish socio-economic classification (in Swedish, with English summary). Orebro 1983.

32 Wamala SP, Wolk A, Orth-Gomér K. Determinants of obesity in relation to socioeconomic status among middle-aged Swedish women. Prev Med 1997;26:734-44.

33 Padyab M, Malmberg G, Norberg M, et al. Life course socioeconomic position and mortality: a population register-based study from Sweden. Scand J Public Health 2013:41:785-91.

34 Lawson DW, Makoli A, Goodman A. Sibling configuration predicts individual and descendant socioeconomic success in a modern post-industrial Society. PLoS One 2013;8:e73698

35 Koupil I, Lawson DW, Goodman A. Low fertility increases descendant socioeconomic position but reduces long-term fitness in a modern post-industrial Society. Proc $R$ Soc B Biol Sci 1746;2012:4342-51.

36 MacKay DF, Smith GCS, Dobbie R, et al. Gestational age at delivery and specia educational need: retrospective cohort study of 407,503 schoolchildren. PLoS Med 2010;7:e1000289-10.

37 Yang S, Platt RW, Kramer MS. Variation in child cognitive ability by week of gestation among healthy term births. Am J Epidemiol 2010;171:399-406.

38 Downey DB. Number of siblings and intellectual development: the resource dilution explanation. Am Psychol 2001;56:497-504.

39 Keith VM, Finlay B. The impact of parental divorce on children's educational attainment, marital timing, and likelihood of divorce. J Marriage Fam 1988:50:797-809
40 Ely M, Richards MPM, Wadsworth MEJ, et al. Secular changes in the association of parental divorce and children's educational attainment - evidence from three British birth cohorts. J Soc Policy 1999;28:437-55.

41 Kristensen P, Bierkedal T. Explaining the relation between birth order and intelligence. Science 2007;316:1717

42 Price J. Parent-child quality time: does birth order matter? J Hum Resour 2008:43:240-65.

43 Ekeus C, Lindstrom K, Lindblad F, et al. Preterm birth, social disadvantage, and cognitive competence in Swedish 18- to 19-year-old men. Pediatrics 2010;125:e67-73.

44 Moster D, Lie RT, Markestad T. Long-Term medical and social consequences of preterm birth. N Engl J Med 2008;359:262-73.

45 Hannah ME. Postterm pregnancy: should all women have labour induced? A review of the literature. Fetal Matern Med Rev 1993:5:3-17.

46 Huleihel M, Golan H, Hallak M. Intrauterine infection / inflammation during pregnancy and offspring brain damages : possible mechanisms involved. Reprod Biol Endocrinol 200 2004;8:1-8.

47 Kabbur PM, Herson VC, Zaremba S, et al. Have the year 2000 neonatal resuscitation program guidelines changed the delivery room management or outcome of Meconium-Stained infants? J Perinatol 2005:25:694-7.

48 Eide MG, Øyen N, Skjærven R, et al. Associations of birth size, gestational age, and adult size with intellectual performance: evidence from a cohort of Norwegian men. Pediatr Res 2007:62:636-42.

49 El Marroun H, Zeegers M, Steegers EAP, et al. Post-Term birth and the risk of behavioural and emotional problems in early childhood. Int J Epidemiol 2012;41:773-81

50 Abel KM, Dalman C, Svensson AC, et al. Deviance in fetal growth and risk of autism spectrum disorder. Am J Psychiatry 2013;170:391-8.

51 Mackenbach JP. Genetics and health inequalities: hypotheses and controversies. $J$ Epidemiol Community Health 2005;59:268-73.

52 Mackenbach JP. New trends in health inequalities research: now it's personal. Lancet 2010;376:854-5.

53 Goodman A, Koupil I. Social and biological determinants of reproductive success in Swedish males and females born 1915-1929. Evol Hum Behav 2009:30:329-41. 


\section{Correction: Early-life social and health determinants of adult socioeconomic position: associations and trends across generations}

Hossin MZ, Björk J, Koupil I. Early-life social and health determinants of adult socioeconomic position: associations and trends across generations. J Epidemiol Community Health 2020;74:412-20.

Some confidence intervals, both in the text and tables 3 and 4, were inadvertently distorted during the process of production. The online version has been corrected.

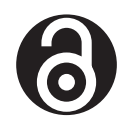

\section{OPEN ACCESS}

Open access This is an open access article distributed in accordance with the Creative Commons Attribution Non Commercial (CC BY-NC 4.0) license, which permits others to distribute, remix, adapt, build upon this work non-commercially, and license their derivative works on different terms, provided the original work is properly cited, appropriate credit is given, any changes made indicated, and the use is non-commercial. See: http://creativecommons.org/licenses/by-nc/4.0/.

(C) Author(s) (or their employer(s)) 2021. Re-use permitted under CC BY-NC. No commercial re-use. See rights and permissions. Published by BMJ.

J Epidemiol Community Health 2021;75:604. doi:10.1136/jech-2019-213209corr1

D) Check for updates 